Artigo de Pesquisa

\title{
Responsabilidade Ambiental, Distância Psicológica e Consumo Ambiental: Mediação em Estudantes de Contabilidade
}

\author{
Environmental Responsibility, Psychological Distance, and Environmental \\ Consumption: Mediation in Accounting Students
}

\section{RESUMO}

Objetivo: este estudo teve como objetivo analisar a relaçáo entre a distância psicológica com o consumo ambiental, consubstanciado na intenção de compra e na lealdade a produtos pró-ambientais, mediadas pela responsabilidade ambiental. Métodos: foram analisadas 113 respostas obtidas por meio de uma survey realizada junto aos acadêmicos do curso de Ciências Contábeis utilizando-se da técnica de modelagem de equaçóes estruturais para identificar as relaçóes propostas e o possível efeito mediador existente entre os construtos. Resultados: os resultados ilustram a existência de mediaçáo parcial da responsabilidade ambiental na relaçáo entre distância psicológica com a intensidade de compra e total com a lealdade dos consumidores. A não rejeição da hipótese de pesquisa expóe a importância da análise de elementos psicológicos frente ao comportamento de consumo de produtos pró-ambientais. Conclusóes: as contribuiçóes teóricas indicam que a responsabilidade ambiental é capaz de promover o consumo de produtos pró-ambientais. Em termos práticos, cursos de Ciências Contábeis podem incorporar discussóes sobre valores éticos socioambientais, expandindo os debates em sala de aula sobre responsabilidade ambiental para além dos aspectos financeiros voltados especificamente para a criaçáo de valor econômico para a organização.

Palavras-chave: distância psicológica; responsabilidade ambiental; ciências contábeis.

1. Universidade Federal do Paraná, Programa de Pós-Graduação em Contabilidade, Brasil.

Como citar: Meurer, A. M., Jesus, C. V. de, \& Panhoca, L. (2021). Responsabilidade ambiental, distância psicológica e consumo ambiental: Mediação em estudantes de contabilidade. Revista de Administração Contemporânea, 25(4), e190223. https://doi.org/10.1590/1982-7849rac2021 190223.por

\begin{abstract}
Alison Martins Meurer ${ }^{1}$ Cristina Viana de Jesus ${ }^{10}$ Luiz Panhoca ${ }^{10}$
\end{abstract}

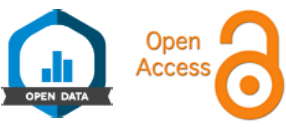

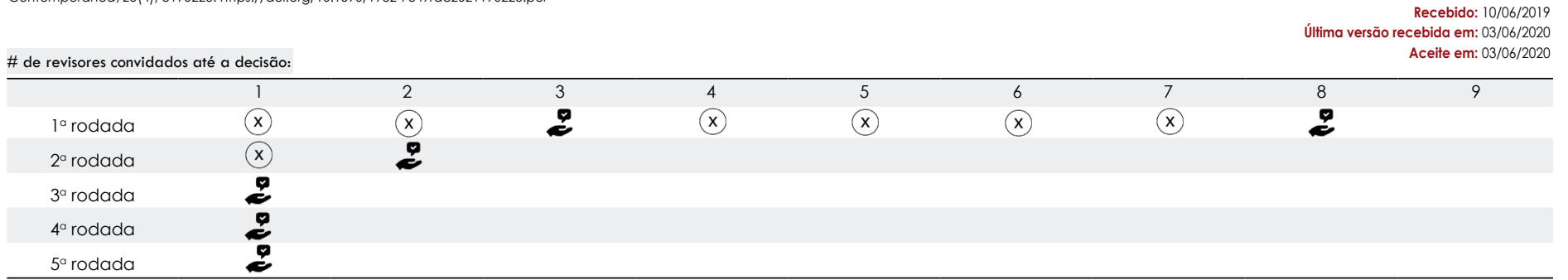

Objective: this study aimed at analyzing the relationship between psychological distance and environmental consumption, embodied in the intention to purchase and loyalty to pro-environmental products, mediated by environmental responsibility. Methods: 113 responses obtained through a survey conducted with academics from the Accounting Sciences course were analyzed, using the structural equation modeling technique to identify the proposed relationships and the possible mediating effect between the constructs. Results: the results illustrate the existence of partial mediation of environmental responsibility in the relationship between psychological distance and the intensity of purchase and total with the loyalty of consumers. The non-rejection of the research hypothesis exposes the importance of analyzing psychological elements regarding to the consumption behavior of pro-environmental products. Conclusions: theoretical contributions indicate that environmental responsibility is capable of promoting the consumption of pro-environmental products. In practical terms, Accounting courses can incorporate discussions about socio-ethical-environmental values, expanding classroom debates about environmental responsibility beyond the financial aspects specifically aimed at creating economic value for the organization.

Keywords: psychological distance; environmental responsibility; accounting sciences.

Classificaçāo JEL: M4, J13, P46

Editor-chefe: Wesley Mendes-Da-Silva (Fundação Getulio Vargas, EAESP, Brasil) (1) areceristas: André G. C. Machado (Universidade Federal da Paraíba, CCSA, Brasil)

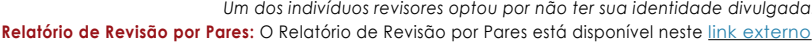
ecebido: 10/06/2019 bida em: 03/06/2020 Aceite em: 03/06/2020 


\section{INTRODUÇÃO}

Há diversas razóes que apontam os efeitos devastadores das ações empresariais e humanas decorrentes da exploração do meio ambiente, o que tem despertado na sociedade um incentivo na adesão ao consumo ético-ambiental, que, por sua vez, impóe sobre as organizaçóes demandas para o aprimoramento de suas estratégias e esquemas de proteção ambiental, a partir de uma conduta socialmente responsável, legitimada e de interação harmônica com o meio ambiente (Kautish \& Sharma, 2019; Shafiei \& Maleksaeidi, 2020).

Nesse contexto, nota-seque as empresasvêm ajustando a oferta de produtos e serviços para um posicionamento ecologicamente correto (Global Industry Analysts, 2013). Os governos também aumentaram o número e o escopo das regulamentaçóes ambientais (United States of America, 2015). Essas preocupaçóes advêm da maximização do poder de consumo, que, fomentando o crescimento industrial, tem se apresentado como um elemento agravante das ameaças de degradação ao meio ambiente e de mudanças climáticas (Ariztía et al., 2014). Assim, debates acerca desta temática e do consumo consciente passaram a permear com mais intensidade as pautas sociais e políticas, promovendo mudanças nas legislaçóes ambientais e no consumo de marcas e produtos pró-ambientais (Ariztía et al., 2014; Chen, 2011).

Especificamente na esfera de consumo, parte dos consumidores tem impressóes positivas e simpatias por produtos pró-ambientais, mas suas intençóes e hábitos de compras permanecem vinculados à percepção tradicional, que consiste em práticas que náo observam aspectos ambientais advindos dos serviços ou produtos adquiridos (White, MacDonnell, \& Ellard, 2012). A dinâmica custobenefício tem sido apontada como uma das principais barreiras para o ingresso nesse nicho de consumo, uma vez que o desembolso financeiro, o tempo e o esforço físico ou mental vinculados aos produtos pró-ambientais podem desencorajar as pessoas a modificar suas práticas de consumo (Gordon-Wilson \& Modi, 2015).

A mudança das práticas de consumo tradicionais para uma postura ambientalmente responsável enseja esforços e mudanças sociais, alicerçados em açóes educacionais adaptadas à cultura de cada grupo social (Sacchi, Riva, \& Aceto, 2016; Yu, Yu, \& Chao, 2017). Brügger, Morton e Dessai (2016) defendem que a resistência à adoção de hábitos de consumo ambientalmente responsáveis e éticos está na sensação de que as alteraçôes ambientais estáo distantes, em tempos e lugares remotos, e que não impactam diretamente a vida dos indivíduos.

Essa impressão de distanciamento caracteriza a distância psicológica, a qual indica que um objeto ou fenômeno percebido próximo ao eu tende a ser tratado de modo concreto e desperta preocupaçóes mais intensas, enquanto objetos ou fenômenos distantes são vistos como algo abstrato (Trivedi, Patel, \& Acharya, 2018). Dessa maneira, se as mudanças ambientais fossem vistas como próximas e concretas, o comportamento dos consumidores estaria mais propenso a práticas de consumo ético (McDonald, Chai, \& Newell, 2015). Dessa maneira, a percepção longínqua das consequências ambientais é uma das principais barreiras para a conscientizaçáo, na medida em que os efeitos e os indicadores ambientais exigem a comparação entre pontos de observação ao longo dos anos em uma escala macro ou micro ambiental, geográfica e temporal (Lecours et al., 2015; Trenberth, 2012).

Outro ponto de vista defendido por entidades como o Institute of Medicine (Institute of Medicine (US), Roundtable on Environmental Health Sciences, Research, and Medicine, 2007) e pesquisadores como Vitell (2015) pauta que a responsabilidade ambiental das pessoas está relacionada à ética e à responsabilidade social, que podem ser associadas a padróes e a princípios morais vinculados às compras, ao uso e aos descartes de bens e serviços. Nesse enfoque, a prática de consumo ético é vista como julgamento moral (Gilead, Liberman, \& Maril, 2014) realizado cotidianamente e que observa as consequências individuais, a postura ética e as ações coletivas alinhadas a padróes socialmente autorresponsáveis (Vitell, 2015; Yu et al., 2017). Essa perspectiva defende que fomentar a responsabilidade ambiental é um dos caminhos mais eficazes para promover o consumo ambiental.

Referente aos consumidores brasileiros, a pesquisa anual de análise de consumo consciente realizada pela Confederação Nacional de Dirigentes Lojistas (CNDL) e pelo Serviço de Proteção ao Crédito (Serviço de Proteção ao Crédito [SPC], 2019) mostrou que em 2019 cerca de 97\% dos entrevistados possuíam dificuldades em adotar práticas de consumo consciente e ambientalmente responsável. O Indicador de Consumo Consciente (ICC) de 2019 foi de $73,30 \%$, representando um perfil de consumo em transição para uma postura socioambiental responsável.

O ICC é calculado a partir do comportamento dos consumidores, sendo dividido em três subindicadores, respectivamente denominados de práticas financeiras, práticas ambientais e práticas de engajamento e responsabilidade social. Os resultados do estudo destacam o fato de que os mais jovens apresentam os menores percentuais de comportamento consciente e responsável em todos os subindicadores.

Assim como na maioria dos países considerados emergentes, os mais jovens representam uma grande parcela da população. Em 2018, cerca de $42,90 \%$ dos brasileiros possuíam menos de 30 anos (Instituto Brasileiro de Geografia e Estatística [IBGE], 2020). Esse grupo 
populacional representa a força de trabalho e o mercado consumidor presente e futuro, cabendo a estes elevada parcela de contribuição para a garantia da sobrevivência do planeta (Mohiuddin, Al Mamun, Syed, Masud, \& Su, 2018).

Nesse sentido, diferentes estudos têm sido conduzidos junto às faixas etárias mais jovens a fim de compreender seu comportamento de consumo para delinear açóes que fomentem a consciência e a responsabilidade ambiental (e.g., Shafiei \& Maleksaeidi, 2020; Yu et al., 2017). Particularmente os universitários têm ocupado destaque nessas pesquisas, pois há evidências na literatura que indicam que os comportamentos moldados no contexto universitário tendem a ser manifestados no ambiente de trabalho e nos demais contextos sociais (Meriac, 2012). Desse modo, o ensino superior é percebido como uma plataforma sólida, capaz de fomentar e orientar os indivíduos a adotarem comportamentos pró-ambientais (Khan, Fatima, \& Bose, 2019).

Algumas pesquisas têm observado especificamente os estudantes pertencentes aos cursos da área de negócios, argumentando que esses futuros profissionais serão responsáveis pela produção, distribuição e consumo de produtos pró-ambientais, bem como pela promoção da sustentabilidade e da responsabilidade social corporativa (Khan et al., 2019; Mohiuddin et al., 2018). Como exemplo tem-se o curso de Ciências Contábeis, foco desta pesquisa, que está sob o escopo da área de negócios e tem recebido fortes críticas nas últimas décadas por não compartilhar entre seus acadêmicos e profissionais atitudes alinhadas ao convívio social ético, por vezes ultrapassando os limites da integridade moral (Kelly \& Alam, 2009; McCabe, Butterfield, \& Treviño, 2006).

Kelly e Alam (2009) reconhecem a necessidade de observar o comportamento e a formaçáo dos acadêmicos da área contábil frente às questóes ambientais e induzem preocupaçóes sobre como a educação ambiental e sustentável tem sido ancorada sob o enfoque de criação de valor econômico, em detrimento da promoção de valores éticos socioambientais. Acredita-se que essa abordagem estritamente econômica que norteia os cursos de Ciências Contábeis possa distanciar os acadêmicos dos comportamentos pró-ambientais, sendo a responsabilidade ambiental um contrapeso dessa relação.

Logo, a abordagem da distância psicológica, da responsabilidade ambiental e do consumo ambiental em futuros contadores é importante para compreender como esse ator organizacional, responsável pela geração de informaçóes e capaz de interferir na responsabilidade social e na sustentabilidade empresarial, pauta sua postura de consumo na vida particular. Desse modo, defende-se que o caráter técnico do curso de Ciências Contábeis precisa oportunizar a discussão e a busca por espaços que também sejam responsáveis pela esfera social, pois a Contabilidade deriva da interação humana.

Nesse sentido, percebe-se que existe um cenário evolutivo que induz a avançar as discussões em relação à temática, incentivando a investigação conjunta dessas perspectivas pautadas na relação de elementos éticos e psicológicos frente ao consumo ambiental, buscando-se compreender: Qual a relação entre distância psicológica e o consumo ambiental mediada pela responsabilidade ambiental de estudantes do curso de bacharelado em Ciências Contábeis? Logo, o objetivo do estudo consiste em analisar a relaçáo entre a distância psicológica e o consumo ambiental mediada pela responsabilidade ambiental de estudantes do curso de bacharelado em Ciências Contábeis. Nesta investigaçáo, o termo 'consumo ambiental' é entendido como a intenção de compra e a lealdade a produtos próambientais.

A pesquisa apresenta três principais contribuiçóes. Primeiro, a propensão do indivíduo em aderir ao consumo de produtos pró-ambientais tem sido abordada na literatura a partir de variáveis socioeconômicas, visando à identificação dos motivadores dessa adesão por meio da análise do gênero, faixa etária, classe social, nível de formação, entre outras características objetivas. Eckhardt, Belk e Devinney (2010), Ferraz, Romero, Rebouças e Costa (2016) e Shafiei e Maleksaeidi (2020) são exemplos de estudos direcionados nesse enfoque.

Esta pesquisa contribui e avança em relação à temática, na medida em que alicerça suas discussôes em diferentes elementos subjetivos, como as dimensóes da responsabilidade ambiental, indicando que as estratégias de engajamento de novos consumidores com produtos pró-ambientais são afetadas pelas respostas psicológicas e pela percepção do indivíduo no que tange às mudanças ambientais. Essas introspecçốes são delimitadas neste estudo aos jovens universitários de um curso pertencente à área de negócios, compondo a amostra da pesquisa.

A segunda contribuição diz respeito ao estudo conjunto da intençáo de compra e da lealdade a produtos pró-ambientais. Estudos anteriores, em sua maioria, têm observado esses elementos de modo dicotômico, sem explorar variáveis precedentes que podem afetar a intençáo de compra e a lealdade a produtos pró-ambientais de forma simultânea.

A terceira e principal contribuição da pesquisa consiste em processar informaçóes e identificar padróes comportamentais de consumo em uma amostra que em última análise consiste nos cidadãos do futuro. Ao propor reflexóes sobre elementos atrelados ao comportamento de consumo desses jovens estudantes pertencentes a um curso 
da área de negócios, açóes educativas com vistas à correção de comportamentos futuros podem ser propostas.

Além disso, a necessidade de compreender o comportamento de compras de produtos pró-ambientais é oportuna devido aos avanços ambientais, científicos e de comunicação, como a internet e as mídias sociais, aumento da conscientização e preocupação dos consumidores com questóes ambientais (Groening, Sarkis, \& Zhu, 2018). Esses elementos caracterizam uma parcela da sociedade contemporânea que se esforça em ajustar seu comportamento de consumo a padróes ecologicamente sustentáveis.

Os resultados da pesquisa contribuem para o avanço da temática visto que reforçam a importância de observar elementos psicológicos frente à intençáo de compra e a lealdade do consumidor a produtos pró-ambientais, pois a distância psicológica e a responsabilidade ambiental mostraram-se preditores e intermediadores dessa postura pró-ambiental. Açóes educativas amparadas na diminuição da distância psicológica podem ser implementadas a fim de promover a responsabilidade ambiental, a intenção de compra e a lealdade a produtos pró-ambientais.

A próxima seção deste estudo apresenta a fundamentação teórica e o background que embasa a hipótese desta pesquisa. Em seguida, são descritos os elementos metodológicos, os resultados, as observaçóes finais e as principais implicações da pesquisa.

\section{FUNDAMENTAÇÃO TEÓRICA}

\section{Distância psicológica}

O conceito de distância psicológica está alicerçado na teoria do nível de interpretação (construal level theory CLT), que analisa as percepçooes do indivíduo em relação aos acontecimentos passados ou futuros e ao grau de abstraçáo - nível de interpretação - atribuído ao objeto analisado. Por se tratar de uma teoria advinda da Psicologia Social, a CLT aborda o comportamento humano por meio das interpretaçóes mentais do indivíduo e da proximidade ou distância que são relacionadas aos acontecimentos analisados (Trope \& Liberman, 2010).

Trope e Liberman (2010) expóem que situações não percebidas no presente são criadas mentalmente pelas pessoas por meio das interpretaçóes mentais. Os níveis de interpretaçóes referentes ao grau de abstração atribuído aos fatos são diferentes entre os indivíduos, pois o grau de abstração origina-se por meio das percepções pessoais (McDonald et al., 2015). Dessa forma, fatos pertencentes a outras dimensões espaciais, temporais, sociais ou hipotéticas tendem a ser construídos mentalmente e percebidos como abstratos e distantes (Brügger et al., 2016; Trope \& Liberman, 2010).

Conceitualmente, a dimensão espacial relaciona-se aos aspectos locais, isto é, o quanto algo pode acontecer perto ou longe do indivíduo. A temporal refere-se ao tempo, isto é, se para determinado fato acredita-se que a ocorrência se dará no futuro próximo ou distante. A distância social está atrelada à percepção de proximidade dos eventos e dos seus efeitos inerentes ao próprio indivíduo e pessoas próximas ou grupos sociais distantes. Por fim, a dimensão hipotética refere-se ao grau de incerteza de ocorrência de determinado acontecimento (Trope \& Liberman, 2010). Portanto, para McDonald, Chai e Newell (2015), as "dimensóes representam as maneiras pelas quais um objeto pode ser distanciado do eu no aqui e agora" e consubstanciado em criaçôes mentais (McDonald et al., 2015, p. 110).

Pesquisas apontam haver inter-relaçóes entre tais dimensóes da distância psicológica. Isso significa que o modo com que algo é representado em termos espaciais também pode estar relacionado aos aspectos sociais, temporais e/ou hipotéticos (McDonald et al., 2015; Spence, Poortinga, \& Pidgeon, 2012; Trope \& Liberman, 2010). Brügger et al. (2016) argumentam que essas representaçóes orientam julgamentos e decisóes subsequentes, moldando o modo de agir e pensar do indivíduo.

No que tange aos aspectos ambientais, Spence, Poortinga e Pidgeon (2012) expóem que uma parcela da população possui elevado grau de incerteza quanto às mudanças climáticas e creem que se ocorrerem, afetarão locais distantes, em um futuro longínquo e com indivíduos desconhecidos. Logo, a distância psicológica em suas quatro dimensôes caracteriza-se como um dos principais preditores do comportamento ético ambiental (McDonald et al., 2015). A baixa percepçáo dos impactos ambientais faz com que o comportamento do indivíduo seja direcionado às práticas tradicionais de consumo e a não se envolver com políticas pró-ambientais (Singh, Zwickle, Bruskotter, \& Wilson, 2017), sendo evidenciada a importância desse construto nas pesquisas que almejam verificar o comportamento do consumidor e a relaçáo com o meio ambiente.

\section{Responsabilidade ambiental}

A compra de produtos pró-ambientais é vista como um julgamento moral que caracteriza o princípio da responsabilidade e comprometimento com o meio ambiente. Incorpora-se à responsabilidade ambiental o conjunto de princípios morais ambientais que caracterizam a ética ambiental, juntamente com dois padróes de responsabilidade, o autorresponsável e o social. O primeiro é derivado do altruísmo e da espontaneidade relacionados às ações que fazem o sujeito sentir-se bem consigo mesmo. $\mathrm{O}$ 
segundo origina-se das pressóes sociais por padróes e atitudes aceitáveis de engajamento ambiental (Joshia \& Rahman, 2015; Yu et al., 2017).

A responsabilidade ambiental tem sido tratada na literatura como sinônimo de construto que caracteriza o comportamento ético do consumidor, visto como os valores que orientam o indivíduo para obtençáo, uso e descarte de bens e serviços (Kautish \& Sharma, 2019). Nesse contexto, o comportamento ético dos consumidores vem sendo observado sob diferentes enfoques. No âmbito econômico, cresce o número de organizaçóes que buscam evidenciar uma postura responsável com o meio ambiente e com a sociedade. No contexto acadêmico, estudos têm fornecido evidências acerca da razão da mudança de postura da sociedade frente aos impactos ao meio ambiente, com destaque para os preditores de comportamentos éticos e pro-ambientais (Afonso, Bornia, Echegaray, \& Andrade, 2016; Ariztía et al., 2014; Chen, 2011; Eckhardt, Belk, \& Devinney, 2010; Fakhrudin, Karyanto, \& Ramli, 2018; Gordon-Wilson \& Modi, 2015; Kautish \& Sharma, 2019; Shafiei \& Maleksaeidi, 2020; Vitell, 2015).

Eckhardt et al. (2010), por exemplo, utilizaram métodos qualitativos e abordagem interpretativista para analisar o comportamento dos consumidores em relação à utilização de produtos não ambientais. As discussóes dos autores são oriundas da baixa proporção de mercado ocupada por produtos pró-ambientais. As conclusóes apontam que apesar de haver consciência ambiental por parte dos consumidores, o consumo ético é moldado pela situação econômica, educação política e condições de desenvolvimento e de trabalho dos países. O consumo de produtos pró-ambientais por vezes é considerado como um luxo e ocasiona acréscimos financeiros que inibem a ampliação do mercado de consumo.

Afonso, Bornia, Echegaray e Andrade (2016) utilizaram a teoria da resposta ao item (TRI) na mensuração do comportamento sustentável dos consumidores de uma amostra composta por 250 adultos com faixa etária entre 18 a 69 anos. A partir de técnicas quantitativas, os autores identificaram que o comportamento sustentável pode ser dividido em etapas que seguem um roteiro. São priorizadas as açóes simples que requerem menos dispêndio financeiro e de tempo, para depois ser adotada uma postura mais consciente em relação ao consumo, como a compra de produtos orgânicos e o engajamento em debates referentes à temática.

Kautish e Sharma (2019) analisaram as relações funcionais entrevaloresterminais einstrumentais, consciência ambiental e intençóes comportamentais para a aquisição de produtos ecológicos na Índia. Os valores terminais e instrumentais mostraram-se positivamente relacionados com a consciência ambiental e em menor intensidade com as intenções comportamentais. Embora os aspectos terminais tenham se apresentado como importantes preditores da consciência ambiental e das intençôes comportamentais positivas, são os valores instrumentais que exercem um papel de destaque frente à decisão de consumo. Assim, é importante que as vantagens do consumo de produtos próambientais sejam expostas de forma que os impactos na vida do consumidor possam ser vislumbrados em curto prazo, visto que o valor instrumental se apresenta como o principal determinante das intenções comportamentais.

Shafiei e Maleksaeidi (2020) verificaram os fatores atrelados ao comportamento pró-ambiental de 310 universitários iranianos. Os resultados indicaram que os fatores que se relacionam com o comportamento próambiental estáo consubstanciados positivamente na autoeficácia, recompensas percebidas e atitude ambiental. Por outro lado, há relação negativa com os custos de respostas percebidos pelos respondentes, como, por exemplo, a sensação de desembolsos financeiros mais elevados frente à adoção de práticas pró-ambientais. Além disso, variáveis como gênero, estado civil e residência em região urbana ou rural não condicionam o comportamento pró-ambiental, sendo que o curso e o grau de formaçáo, graduação ou pós-graduação, são capazes de direcionar as atitudes dos respondentes inerentes à ética ambiental.

Assim, a literatura tem reforçado por meio das diferentes descobertas científicas os efeitos das variáveis psicológicas sobre o comportamento dos consumidores em relação a produtos pró-ambientais, à medida que as decisôes de compra e uso destes produtos envolvem a ética, a responsabilidade social e a autorresponsabilidade do sujeito.

\section{Intenção de compra e lealdade dos consumidores}

A intençáo de compra é caracterizada como um plano consciente em que sáo realizados julgamentos mentais e são direcionados os comportamentos futuros das pessoas (Fakhrudin et al., 2018; Trivedi et al., 2018). Para Ferraz et al. (2016), esta variável medeia a relação entre atitudes e comportamentos dos consumidores, pois age "como uma espécie de índice que uma pessoa estaria disposta a tentar desempenhar em prol de uma ação" (Ferraz, Romero, Rebouças, \& Costa, 2016, p. 609). A importância em estudar este construto está no poder preditivo do comportamento dos consumidores e na análise dos fatores que estáo relacionados às suas tomadas de decisóes (Lee, 2017; Yu et al., 2017).

Outro elemento a ser observado no mercado de consumo é a lealdade que caracteriza o quanto um indivíduo está "profundamente comprometido em consumir um produto/serviço de forma consistente, realizando repetidas 
compras da mesma marca, e desprezando influências situacionais e esforços de marketing" (Oliver, 1999, p. 34). Para Yu, Yu e Chao (2017) e Lee (2017), a competitividade e a variedade de opçóes fazem com que a intençáo de compra e a lealdade do consumidor a produtos ambientalmente éticos recebam mais atenção por parte das empresas. Oliver (1999) destaca que a lealdade aos produtos pró-ambientais está relacionada à responsabilidade ambiental do indivíduo, oportunizando a verificaçáo em conjunto da relaçáo desta com a lealdade e a intençáo de compra.

Ferraz et al. (2016) verificaram a relação existente entre atitude, intençáo de compra e comportamento de compra ecologicamente conscientes. A análise dos dados indicou haver relação entre as três variáveis, sendo que o preço e a qualidade percebida são os fatores mais relevantes na transição entre a intenção de compra para a compra efetiva do consumidor.

Por fim, Yu et al. (2017) analisaram o efeito mediador da responsabilidade ambiental na relação entre a distância psicológica com o consumo ambiental. A pesquisa foi realizada por meio da participação de alunos universitários taiwaneses, sendo utilizada a técnica de modelagem de equaçóes estruturais na análise dos dados. Houve relação positiva entre a responsabilidade ambiental com a intenção de compra e a lealdade a produtos ambientalmente éticos. Frente aos achados, Yu et al. (2017) argumentam a necessidade de desenvolver a autorresponsabilidade dos consumidores de forma contínua e ampla com vistas a incentivar os consumidores na aquisição de produtos menos prejudiciais ao meio ambiente.

Com intuito de enriquecer os achados e as discussóes referentes ao consumo de produtos pró-ambientais, esta investigação é norteada pela seguinte hipótese de pesquisa: A relação entre distância psicológica com a intenção de compra e a lealdade a produtos pró-ambientais é mediada pela responsabilidade ambiental.

Com base na hipótese elencada, na Figura 1 é ilustrado o modelo teórico que direciona o estudo.

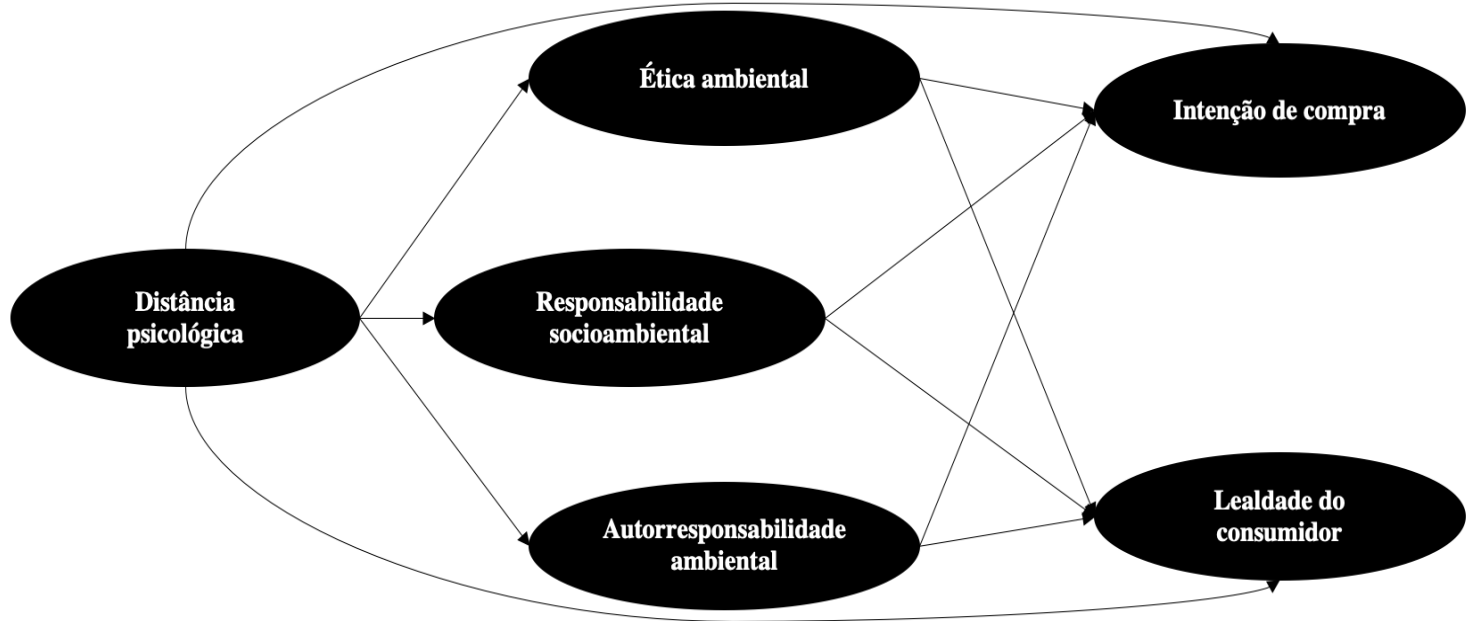

Figura 1. Modelo teórico da pesquisa.

Fonte: elaborado pelos autores.

ApartirdaFigura 1 depreende-sequea responsabilidade ambiental, corporizada pela ética ambiental, responsabilidade socioambiental e autorresponsabilidade ambiental, medeia a relação existente entre a distância psicológica e a intenção de compra e a lealdade do consumidor a produtos próambientais. Tal relacionamento é verificado a partir das três premissas (a), (b) e (c) defendidas por Baron e Kenny (1986).

A premissa (a) considera que as variaçóes nos níveis da variável independente (distância psicológica) afetam significativamente as variaçóes do mediador presumido (ética ambiental, responsabilidade socioambiental e autorresponsabilidade ambiental). $\mathrm{Na}$ premissa (b) as variaçóes do possível mediador (ética ambiental, responsabilidade socioambiental e autorresponsabilidade ambiental) afetam significativamente as variações da variável dependente (intençâo de compra e lealdade do consumidor).

Por fim, a premissa (c) consiste na diminuição ou inexistência dos efeitos diretos significantes entre a variável independente (distância psicológica) e a dependente (intenção de compra e lealdade do consumidor) com a inclusão da presumível variável mediadora (ética ambiental, responsabilidade socioambiental e autorresponsabilidade ambiental), visto que se a inclusão da presumível variável mediadora reduzir o efeito direto a zero, permanecendo 
os efeitos significativos das condições (a) e (b), é possível afirmar a existência de mediação total; caso essa redução não for a zero, então há mediação parcial.

\section{PROCEDIMENTOS METODOLÓGICOS}

Esta pesquisa possui caráter descritivo e abordagem quantitativa, uma vez que os dados foram coletados por meio de survey realizada junto a acadêmicos do curso de bacharelado em Ciências Contábeis de uma universidade pública localizada no sul do Brasil. A população do estudo é náo probabilística, definida por acessibilidade, e consiste em 211 alunos, sendo que 143 participaram da pesquisa e 113 respostas foram consideradas válidas para serem analisadas por estarem respondidas na íntegra.

Os respondentes preencheram um questionário dividido em dois blocos. $O$ primeiro consistiu no instrumento adaptado de Yu et al. (2017), no qual havia questóes referentes ao comportamento dos consumidores em relação a produtos pró-ambientais. Foi utilizada a escala numérica de intensidade de concordância com rótulos nos numeradores das extremidades, sendo 1 = 'náo concordo' e 7 = 'concordo totalmente'. As escalas numéricas permitem o emprego de análises quantitativas, visto que seus valores não cumprem papel estritamente semântico e categórico como a escala Likert. O primeiro e o quarto construtos foram os únicos com quatro afirmativas cada, sendo os demais compostos por cinco afirmativas cada. Assim, o primeiro bloco do instrumento de coleta de dados foi composto por 28 assertivas, conforme exposto no Anexo I. Na Tabela 1 são apresentados os construtos da pesquisa, descrição e exemplificação das assertivas do instrumento de coleta de dados.

Tabela 1. Construtos da pesquisa.

\begin{tabular}{|c|c|c|c|}
\hline \multicolumn{2}{|c|}{ Construto do instrumento de pesquisa } & Descrição & $\begin{array}{l}\text { Exemplificação de assertiva que compóe o } \\
\text { construto }\end{array}$ \\
\hline \multirow{4}{*}{ 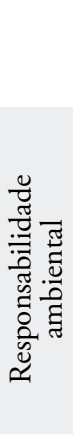 } & Distância psicológica & $\begin{array}{l}\text { Distanciamento psicológico em relação às } \\
\text { mudanças ambientais e climáticas nas dimensóes } \\
\text { temporal, espacial, social e hipotética. }\end{array}$ & $\begin{array}{l}\text { Estou certo de que as mudanças ambientais e } \\
\text { climáticas realmente estáo acontecendo. }\end{array}$ \\
\hline & Responsabilidade socioambiental & $\begin{array}{l}\text { Engajamento e pressão social relacionados ao } \\
\text { comportamento pró-ambiental. }\end{array}$ & $\begin{array}{l}\text { Participo de atividades que visam a proteger e } \\
\text { melhorar a qualidade do meio ambiente. }\end{array}$ \\
\hline & Ética ambiental & $\begin{array}{l}\text { Compromisso moral com a responsabilidade } \\
\text { ambiental. }\end{array}$ & $\begin{array}{l}\text { Evito comprar produtos potencialmente } \\
\text { prejudiciais ao meio ambiente. }\end{array}$ \\
\hline & Autorresponsabilidade ambiental & $\begin{array}{l}\text { Autopercepçáo e comprometimento com } \\
\text { comportamentos pró-ambientais. }\end{array}$ & $\begin{array}{l}\text { Eu acho que os indivíduos têm a responsabilidade } \\
\text { de proteger o meio ambiente. }\end{array}$ \\
\hline & Intenção de compra & $\begin{array}{l}\text { Propensão de compra de produtos pró- } \\
\text { ambientais. }\end{array}$ & $\begin{array}{l}\text { Em um futuro próximo, planejo comprar } \\
\text { somente produtos com uma marca ecológica. }\end{array}$ \\
\hline \multicolumn{2}{|r|}{ Lealdade do consumidor } & $\begin{array}{l}\text { Frequência e compromisso com o consumo de } \\
\text { produtos pró-ambientais. }\end{array}$ & $\begin{array}{l}\text { Estou disposto a pagar mais dinheiro por } \\
\text { produtos ecológicos. }\end{array}$ \\
\hline
\end{tabular}

Nota. Fonte: Dados da pesquisa.

Cabe ressaltar que o construto responsabilidade ambiental é constituído de três construtos de segunda ordem (responsabilidade socioambiental, ética ambiental e autorresponsabilidade ambiental). Já o segundo bloco foi destinado à caracterização dos respondentes, com questóes referentes ao perfil do participante.

O questionário foi submetido a um processo de validação em setembro de 2017 consubstanciado em três etapas: (1) validação de conteúdo; (2) validação aparente; e (3) pré-teste. A validação de conteúdo foi realizada por dois professores e pesquisadores vinculados a um programa de pós-graduação stricto sensu e que possuem histórico de pesquisa na área de interesse. O objetivo desta etapa foi verificar se o conteúdo das assertivas possuía capacidade de caracterizar os construtos abordados pela pesquisa. Algumas contribuiçóes foram direcionadas para o aprimoramento das assertivas, por exemplo, ex ante - "Sinto-me mais confortável quando uso produtos ecológicos em vez de produtos normais" e ex post - "Sinto-me mais confortável quando uso produtos ecológicos ao invés de produtos não ecológicos".

A validação aparente foi realizada por dois pesquisadores com histórico de pesquisa e experiência docente em cursos de graduação, com o objetivo de verificar a 
compreensão da escala. Assim, foi solicitado individualmente que os participantes realizassem a leitura em voz alta de cada assertiva e que em seguida fosse exposta a sua compreensão sobre o item abordado. Novas contribuições foram obtidas nessa etapa, a exemplo da sugestão de que a assertiva "Eu apoio organizações não governamentais que trabalham para minimizar os impactos negativos sobre o meio ambiente" fosse modificada para "Eu apoio organizaçôes náo governamentais que trabalham para minimizar os impactos negativos causados por outras organizações ao meio ambiente". Por fim, foi realizado um pré-teste com nove alunos de graduação e que não compuseram a amostra final da pesquisa. Nesta etapa não houve nenhuma sugestão de melhoria.

A coleta de dados foi realizada in loco em turmas do período noturno, com consentimento dos professores, por meio de questionários impressos e aplicados no mês de novembro de 2017. Optou-se pela coleta presencial para que o maior número possível de respondentes fosse alcançado e para que, caso o participante tivesse alguma dúvida quanto ao objetivo da pesquisa, pudesse esclarecê-la junto aos pesquisadores.

$\mathrm{Na}$ análise dos dados utilizou-se a técnica de modelagem de equaçóes estruturais com modelo de mensuração de mínimos quadrados parciais (PLS-SEM) calculada por meio da variância (VB-SEM). Para Hair, Sarstedt, Ringle e Mena (2012) a utilização do cálculo da VBSEM possibilita ao pesquisador estimar modelos complexos com um número reduzido de componentes amostrais. Tal fato é uma das justificativas à crescente utilização dessa técnica em pesquisas relacionadas às Ciências Sociais Aplicadas, visto que a utilização de dados primários é um dos desafios a serem superados nos estudos dessa área do conhecimento.

O tamanho da amostra adequada para a aplicação da modelagem de equaçóes estruturais foi estimado a partir do software $G^{*}$ Power 3.1.9.2 $2^{\circ}$. Para tanto, definiu-se como mediano o tamanho do effect size $\mathrm{f}^{2}=0,15, \alpha$ err prob $=0,05$ e $1-\beta$ err prob $=0,8$. O tamanho mínimo da amostra retornado foi de 68 respostas. Como se obteve 113 participaçóes válidas, os pré-requisitos à aplicação da técnica PLS-SEM foram atendidos. A verificação dos dados foi norteada pelo protocolo de análise exposto na Tabela 2 .

A análise dos dados foi operacionalizada a partir do software R Studio $1.0 .153^{\circ}$ com uso do pacote plspm.

Tabela 2. Protocolo de análise.

\begin{tabular}{|c|c|c|c|c|}
\hline & Etapa & Objetivo & Parâmetro & Referência \\
\hline \multicolumn{2}{|c|}{ Estatística descritiva } & $\begin{array}{l}\text { Descrever os valores percentuais referentes às } \\
\text { características dos respondentes }\end{array}$ & Não há & Não há \\
\hline \multirow{5}{*}{ 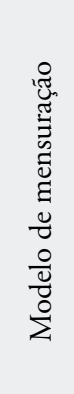 } & $\begin{array}{l}\text { Variância média extraída } \\
\text { (average variance } \\
\text { extracted - AVE) }\end{array}$ & $\begin{array}{l}\text { Medir a porçáo dos dados (nas respectivas variáveis) } \\
\text { que é explicada por cada um dos construtos }\end{array}$ & Valores acima de 0,50 & $\begin{array}{l}\text { Henseler, Ringle e Sinkovics } \\
\text { (2009) }\end{array}$ \\
\hline & DG. Rho & \multirow{3}{*}{$\begin{array}{l}\text { Avaliar a confiabilidade e a capacidade de } \\
\text { agrupamento interno do construto. }\end{array}$} & Valores acima de 0,7 & \multirow{3}{*}{ Sanchez (2013) } \\
\hline & $1^{\circ}$ autovalor & & Valores acima de 1. & \\
\hline & $2^{\circ}$ autovalor & & Valores abaixo de 1. & \\
\hline & $\begin{array}{l}\text { Cargas fatoriais } \\
\text { cruzadas }\end{array}$ & $\begin{array}{l}\text { Avaliar a independência das variáveis latentes } \\
\text { observadas em relaçáo às demais. }\end{array}$ & $\begin{array}{l}\text { Valores acima de } 0,5 \text { e maior } \\
\text { valor do cruzamento. }\end{array}$ & $\begin{array}{l}\text { Hair, Hult, Ringle e Sarstedt } \\
\text { (2014); Sanchez (2013) }\end{array}$ \\
\hline \multirow{4}{*}{ 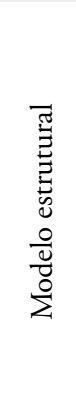 } & $\begin{array}{l}\text { Estimativas dos } \\
\text { coeficientes }\end{array}$ & $\begin{array}{l}\text { Avaliar a significância dos coeficientes e das regressóes } \\
\text { endógenas (teste } t \text { ). }\end{array}$ & $\begin{array}{l}\text { p-value significante em até } \\
10 \% .\end{array}$ & \multirow{2}{*}{ Sanchez (2013) } \\
\hline & $\begin{array}{l}\text { Correlações entre as } \\
\text { variáveis latentes }\end{array}$ & Avaliar a correlação entre as variáveis latentes. & $\begin{array}{l}\text { Correlações relevantes, acima } \\
\text { de } 0,5 \text {. }\end{array}$ & \\
\hline & $\mathrm{R}^{2}$ & $\begin{array}{l}\text { Avaliar o poder explicativo das variáveis exógenas para } \\
\text { as endógenas. }\end{array}$ & $\begin{array}{l}\text { Até } 2 \% \text {, efeito pequeno; acima } \\
\text { de } 2 \% \text { até } 13 \% \text {, efeito médio; } \\
\text { acima de } 13 \% \text { até } 26 \% \text {, efeito } \\
\text { grande. }\end{array}$ & Cohen (1988) \\
\hline & Goodness-of-Fit (GoF) & Verificar o ajustamento do modelo. & Acima de 0,36 . & $\begin{array}{l}\text { Tenenhaus, Vinzi, Chatelin e } \\
\text { Lauro (2005); Sanchez (2013) }\end{array}$ \\
\hline
\end{tabular}

Nota. Fonte: Elaborado pelos autores. 


\section{ANÁLISE DOS DADOS}

\section{Perfil dos respondentes}

O perfil dos respondentes é exposto na Tabela 3, a partir dos percentuais relativos ao gênero, faixa etária, estado civil e ocupação dos respondentes.
Das 113 participações analisadas, 64 (56,64\%) são do gênero masculino. No que concerne à idade, 49 alunos $(43,36 \%)$ possuem até 20 anos. Atualmente, 86 respondentes $(76,10 \%)$ trabalham ou realizam estágio, enquanto 97 discentes $(85,84 \%)$ possuem estado civil solteiro.

Tabela 3. Estatística descritiva.

\begin{tabular}{|c|c|c|c|}
\hline \multicolumn{4}{|c|}{ Perfil dos respondentes } \\
\hline \multicolumn{2}{|c|}{ Gênero } & \multicolumn{2}{|c|}{ Atualmente trabalha ou realiza estágio? } \\
\hline Masculino & $56,64 \%$ & Sim & $76,10 \%$ \\
\hline Feminino & $43,36 \%$ & Não & $23,90 \%$ \\
\hline \multicolumn{2}{|c|}{ Qual sua faixa etária? } & \multicolumn{2}{|c|}{ Qual o seu estado civil? } \\
\hline Até 20 anos & $43,36 \%$ & Solteiro & $85,84 \%$ \\
\hline $21-25$ anos & $33,63 \%$ & Casado & $10,62 \%$ \\
\hline $26-30$ anos & $14,16 \%$ & Divorciado & $0,88 \%$ \\
\hline $31-35$ anos & $4,42 \%$ & Relação estável & $1,77 \%$ \\
\hline $36-40$ anos & $2,66 \%$ & Viúvo & $0,88 \%$ \\
\hline Acima 40 anos & $1,77 \%$ & & \\
\hline
\end{tabular}

Nota. Fonte: dados da pesquisa.

\section{Análise do modelo de mensuração}

A técnica de modelagem de equações estruturais é composta por dois modelos: mensuração e estrutural. $\mathrm{O}$ modelo de mensuração busca analisar a validade interna dos construtos a partir da unidimensionalidade dos indicadores, cujo objetivo é identificar se as assertivas refletem a variável latente a qual se propóem medir (Hair, Hult, Ringle \& Sarstedt, 2014), sendo esta verificação efetuada a partir do DG. Rho e do primeiro e segundo autovalores (Sanchez, 2013).

O DG. Rho verifica a variância da soma dos indicadores da variável latente. Valores acima de 0,70 indicam a existência de unidimensionalidade no construto. Esse indicador é considerado mais eficiente que o Alpha de Cronbach (Sanchez, 2013); em face disto, optou-se somente por analisar o DG. Rho. O primeiro e o segundo autovalores constatam as correlaçóes entre os indicadores, sendo que o primeiro autovalor e o segundo autovalor devem ser, respectivamente, maior e menor que um para indicar a existência de unidimensionalidade.

Inicialmente, foi necessária a exclusão da assertiva 4 da distância psicológica e da assertiva 11 do comportamento ético, por prejudicarem a unidimensionalidade dos construtos. Em seguida, foi realizada a avaliação da consistência interna e da validade convergente, por meio da AVE (Hair et al., 2014). A AVE "mede a quantidade de variância que uma variável latente captura de seus indicadores em relação à quantidade de variância devido ao erro de medição" (Sanchez, 2013, p. 104), sendo que valores acima de 0,50 são considerados apropriados. A Tabela 4 expóe as correlaçóes dos construtos e os indicadores de confiabilidade interna e validação convergente.

A avaliação das correlaçóes dos construtos permite identificar a intensidade com que as variáveis latentes estáo associadas (Sanchez, 2013). A partir da Tabela 4 observa-se que a distância psicológica possui maior nível de associação positiva com a autorresponsabilidade ambiental $(\mathrm{r}=0,393)$. A responsabilidade socioambiental está correlacionada positivamente com a ética ambiental $(r=0,695)$, enquanto a intenção de compra também apresenta coeficientes de associação positivos com a responsabilidade socioambiental $(\mathrm{r}=0,761)$, autorresponsabilidade ambiental $(\mathrm{r}=0,783)$ e lealdade do consumidor $(r=0,701)$. 
Tabela 4. Correlaçóes dos construtos, confiabilidade interna e validação convergente.

\begin{tabular}{|c|c|c|c|c|c|c|}
\hline Variáveis & $\begin{array}{l}\text { Distância } \\
\text { psicológica }\end{array}$ & Ética ambiental & $\begin{array}{c}\text { Respons. } \\
\text { socioambiental }\end{array}$ & $\begin{array}{c}\text { Autorrespons. } \\
\text { ambiental }\end{array}$ & $\begin{array}{l}\text { Intençáa de } \\
\text { compra }\end{array}$ & $\begin{array}{l}\text { Lealdade do } \\
\text { consumidor }\end{array}$ \\
\hline $\begin{array}{l}\text { Distância } \\
\text { psicológica }\end{array}$ & 1,000 & & & & & \\
\hline Ética ambiental & 0,383 & 1,000 & & & & \\
\hline $\begin{array}{l}\text { Responsabilidade } \\
\text { socioambiental }\end{array}$ & 0,303 & 0,695 & 1,000 & & & \\
\hline $\begin{array}{c}\text { Autorrespons. } \\
\text { ambiental }\end{array}$ & 0,393 & 0,672 & 0,703 & 1,000 & & \\
\hline $\begin{array}{l}\text { Intenção de } \\
\text { compra }\end{array}$ & 0,361 & 0,638 & 0,761 & 0,783 & 1,000 & \\
\hline $\begin{array}{l}\text { Lealdade do } \\
\text { consumidor }\end{array}$ & 0,212 & 0,592 & 0,706 & 0,675 & 0,701 & 1,000 \\
\hline DG. Rho & 0,895 & 0,807 & 0,860 & 0,865 & 0,903 & 0,891 \\
\hline $1^{\mathrm{o}}$ autovalor & 2,22 & 2,06 & 2,77 & 2,47 & 3,26 & 3,11 \\
\hline $2^{\circ}$ autovalor & 0,486 & 0,846 & 0,943 & 0,926 & 0,793 & 0,870 \\
\hline AVE & 0,730 & 0,506 & 0,553 & 0,616 & 0,652 & 0,616 \\
\hline
\end{tabular}

Nota. Respons. = Responsabilidade; Autorrespons. = Autorresponsabilidade. Parâmetros (Henseler, Ringle, \& Sinkovics, 2009; Sanchez, 2013): DG. Rho >0,70; ${ }^{\circ}$ autovalor > 1; $2^{\circ}$ autovalor $<1$; AVE $>0,50$. Fonte: dados da pesquisa.

As menores associaçóes são encontradas entre a distância psicológica e as demais variáveis. Nesse sentido, é importante destacar que a correlação está pautada em um pressuposto de relação linear, na qual o incremento em uma variável está associado a uma modificação em outra variável. Por tratar-se de um estudo vinculado ao comportamento humano, que é moldado a partir de diversos elementos e contextos, as relaçóes encontradas podem ser consideradas satisfatórias, tendo em vista que, como Cohen (1988) destaca, correlaçóes entre 0,10 e 0,49 podem ser classificadas como médias ou pequenas a depender da faixa de valores na qual se encontram.

Ao verificar o DG. Rho, nota-se que todos os construtos atendem o parâmetro definido por este indicador, sendo apresentados coeficientes acima de 0,70 . De modo adicional, os critérios definidos para o primeiro e o segundo autovalores foram atendidos, assim como a premissa da AVE. Estes resultados evidenciam a confiabilidade interna dos construtos e confirmam a sua validade convergente.

Para finalizar a avaliação do modelo de mensuração, deve-se examinar a validade discriminante dos indicadores por meio das cargas cruzadas (crossloadings), em que é verificada a independência das variáveis latentes em relação às demais (Hair et al., 2014). Sanchez (2013) cita a necessidade de os carregamentos próprios de cada construto serem superiores aos demais e maiores que 0,50. A Tabela 5 mostra os coeficientes máximos e mínimos das crossloadings próprias e dos demais cruzamentos.

Tabela 5. Validade discriminante - crossloadings.

\begin{tabular}{lcccc}
\hline \multicolumn{1}{c}{ Validade discriminante } & Cargas cruzadas (mínimas) & Cargas cruzadas (máximas) & $\begin{array}{c}\text { Construto associado } \\
\text { (mínimas) }\end{array}$ & $\begin{array}{c}\text { Construto associado } \\
\text { (máximas) }\end{array}$ \\
\hline Distância psicológica & 0,067 & 0,394 & 0,772 & 0,899 \\
Ética ambiental & 0,147 & 0,631 & 0,704 & 0,743 \\
Responsabilidade social & 0,088 & 0,675 & 0,611 & 0,861 \\
Autorresponsabilidade social & 0,306 & 0,658 & 0,773 & 0,840 \\
Intenção de compra & 0,243 & 0,689 & 0,703 & 0,870 \\
Lealdade do consumidor & 0,020 & 0,719 & 0,642 & 0,884 \\
\hline
\end{tabular}

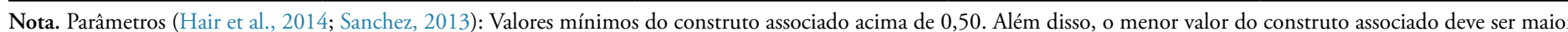
que os valores das cargas cruzadas. Fonte: dados da pesquisa. 
Conforme exposto na Tabela 5, os valores obtidos nas crossloadings são acima de 0,50 , indicando que as assertivas das variáveis latentes conseguem explicar no mínimo $50 \%$ do construto (Sanchez, 2013). De modo geral, as crossloadings são maiores que os valores dos demais construtos, indicando que há independência entre as variáveis latentes estudadas. A partir da análise de confiabilidade interna e das validaçóes convergente e discriminante, é possível afirmar que o modelo de mensuraçáo é adequado e consegue representar as variáveis latentes que se propóe medir.

\section{Modelo estrutural e hipótese da pesquisa}

A avaliação do modelo estrutural e da hipótese de pesquisa é realizada de maneira conjunta. Para verificar se a relaçáo entre a distância psicológica com a intençáo de compra e a lealdade a produtos pró-ambientais é mediada pela responsabilidade ambiental, utilizou-se das premissas (a), (b) e (c) de Baron e Kenny (1986).

Primeiramente foram analisadas as premissas (a) e (b) que consideram os coeficientes de efeitos diretos entre os construtos de caminho que contêm as presumíveis variáveis latentes mediadoras. A premissa (a) visa a identificar se há efeitos diretos e significantes nos coeficientes de caminhos obtidos entre a distância psicológica e as variáveis latentes da responsabilidade ambiental. A premissa (b) avalia a existência de efeitos diretos e significantes entre os coeficientes de caminho da responsabilidade ambiental com a intenção de compra e a lealdade do consumidor. Por meio da Tabela 6 é possível analisar os resultados obtidos.

Tabela 6. Avaliação dos caminhos.

\begin{tabular}{|c|c|c|c|}
\hline Premissa & Caminho & Efeito direto & Conclusão \\
\hline \multirow{3}{*}{ (A) } & Dist. Psic. > E. Ambiental & $0,382^{* * *}$ & \multirow{3}{*}{ Premissa atendida } \\
\hline & Dist. Psic. > Resp. Soc. & $0,302^{* * *}$ & \\
\hline & Dist. Psic. > Autorresp & $0,393^{* * *}$ & \\
\hline \multirow{6}{*}{ (B) } & E. Ambiental > Int. Comp. & $0,032^{* * *}$ & \multirow{6}{*}{ Premissa atendida } \\
\hline & E. Ambiental > Leal. Cons. & $0,102^{* * *}$ & \\
\hline & Resp. Soc. > Int. Comp. & $0,399^{* * *}$ & \\
\hline & Resp. Soc. > Leal. Cons. & $0,416^{* * *}$ & \\
\hline & Autorresp. > Int. Comp. & $0,462^{* * *}$ & \\
\hline & Autorresp. > Leal. Cons. & $0,349^{* * *}$ & \\
\hline
\end{tabular}

Nota. Premissas de Baron e Kenny (1986): (a) as variaçōes nos níveis da variável independente (distância psicológica) afetam significativamente as variaçóes do mediador presumido (ética ambiental, responsabilidade socioambiental e autorresponsabilidade ambiental); e (b) as variaçôes do possível mediador (ética ambiental, responsabilidade socioambiental e autorresponsabilidade ambiental) afetam significativamente as variaçốes da variável dependente (intenção de compra e lealdade do consumidor). Dist. Psic. = Distância psicológica; E. Ambiental = Ética ambiental; Resp. Soc. = Responsabilidade socioambiental; Autorresp. = Autorresponsabilidade ambiental; Int. Comp. = Intençáo de compra; Leal. Cons. $=$ Lealdade do consumidor. ${ }^{* * *}$ indica significância ao nível de $1 \%$. Fonte: dados da pesquisa.

A partir do disposto na Tabela 6, nota-se que todos os coeficientes de caminho que representam os efeitos diretos foramsignificantesaonívelde $1 \%$, sendoatendidasaspremissas (a) e (b). Os resultados indicam haver relação positiva em todas as trajetórias observadas. A distância psicológica exerce maior efeito direto sobre a autorresponsabilidade ambiental $(\beta=0,393 ; \mathrm{p}$-value $<0,01)$, indicando que quanto mais próximo o indivíduo percebe de si as modificações climáticas em termos espacial, temporal, social e hipotético, maior será o nível de autorresponsabilidade refletida em altruísmo e bem-estar. Tal constatação corrobora Brügger et al. (2016) na medida em que a distância psicológica se mostra capaz de influenciar o comportamento e o julgamento dos indivíduos. É corroborada também por McDonald et al. (2015), visto que esta variável se apresenta preditora da responsabilidade ambiental.
A ética ambiental $(\beta=0,102 ; p$-value $<0,01)$ e a responsabilidade socioambiental $(\beta=0,416$; $\mathrm{p}$-value $<0,01)$ exercem maior efeito direto na lealdade do consumidor, indicando que elementos inerentes aos aspectos morais e à pressáo social têm maior capacidade de afetar a lealdade dos participantes do estudo em relaçáo ao consumo de produtos e marcas pró-ambientais. Por outro lado, a intenção de compra é influenciada diretamente e de forma mais intensa pela autorresponsabilidade ambiental $(\beta=0,462$; p-value < 0,01 ), apontando que o anseio em consumir produtos próambientais advém dos julgamentos próprios do indivíduo sobre seu papel e comprometimento com a sociedade.

Com intuito de constatar a existência de mediaçáo por parte da responsabilidade ambiental na relação entre distância psicológica com a intençấo de compra e a lealdade do consumidor, foi realizada a análise da última premissa de Baron e Kenny (1986). A premissa (c) consiste na 
diminuição ou extinçáo do efeito direto significante entre a variável independente e a dependente a partir da inclusão da presumível variável mediadora. As Tabelas 7 e 8 apresentam os valores dos coeficientes de caminho do modelo sem mediação e com mediação, bem como o poder explicativo da rede de relacionamentos sobre as variáveis exógenas.

Tabela 7. Modelo estrutural e avaliação da mediação.

\begin{tabular}{|c|c|c|c|c|c|c|c|c|}
\hline \multirow{3}{*}{ Premissa (c) } & \multirow{3}{*}{$\begin{array}{c}\begin{array}{c}\text { Modelo sem } \\
\text { mediação }\end{array} \\
\text { Efeito direto } \\
\beta\end{array}$} & \multicolumn{6}{|c|}{ Modelo com mediação } & \multirow{3}{*}{$\underset{\text { mediação }}{\mathrm{H}_{1}}$} \\
\hline & & \multicolumn{2}{|c|}{ Efeito direto } & \multicolumn{2}{|c|}{ Efeito indireto } & Efeito total & Efeito med. & \\
\hline & & $\beta$ & $\%$ & $\beta$ & $\%$ & $\beta$ & $\%$ & \\
\hline $\begin{array}{l}\text { Dist. Psic. > Int. } \\
\text { Comp. }\end{array}$ & $0,372^{* * *}$ & $0,045^{* * *}$ & 12,50 & 0,315 & 87,50 & $0,360^{* *}$ & $+87,50$ & Parcial \\
\hline $\begin{array}{l}\text { Dist. Psic. > Leal. } \\
\text { Cons. }\end{array}$ & $0,237^{* *}$ & $-0,090^{* * *}$ & $-42,65$ & 0,303 & 142,65 & $0,211^{* *}$ & $+142,65$ & Total \\
\hline
\end{tabular}

Nota. Premissa de Baron e Kenny (1986): (c) é atendida com a diminuição ou inexistência dos efeitos diretos significantes entre a variável independente (distância psicológica) e a dependente (intençáo de compra e lealdade do consumidor) com a inclusão da presumível variável mediadora (ética ambiental, responsabilidade socioambiental e autorresponsabilidade ambiental). Se ao incluir a presumível variável mediadora o efeito direto for reduzido a zero, permanecendo os efeitos significativos das premissas (a) e (b), é possível afirmar a existência de mediação total; caso essa redução não for a zero, então há mediação parcial. Dist. Psic. = Distância psicológica; Int. Comp. = Intenção de compra; Leal. Cons. $=$ Lealdade do consumidor. $\beta=$ Beta; $\%=$ Percentual do efeito. ${ }^{* *} \mathrm{e}^{* *}$ indicam significância ao nível de $1 \%$ e $5 \%$, respectivamente. Fonte: dados da pesquisa.

Tabela 8. Poder explicativo dos modelos avaliados.

\begin{tabular}{lcc}
\hline \multicolumn{1}{c}{ Construto } & $\mathrm{R}^{2}-$ Modelo sem mediação & $\mathrm{R}^{2}-$ Modelo com mediação \\
\hline Ética ambiental & Não há & $0,146^{* *}$ \\
Responsabilidade socioambiental & Não há & $0,091^{* *}$ \\
Autorresponsabilidade ambiental & Não há & $0,154^{* *}$ \\
Intenção de compra & $0,138^{* *}$ & $0,703^{* *}$ \\
Lealdade do consumidor & $0,056^{* *}$ & $0,571^{* *}$ \\
Goodness-of-Fit (GoF) & 0,25 & 0,45 \\
\hline
\end{tabular}

Nota. $\mathrm{R}^{2}$ = Poder explicativo das variáveis exógenas para as endógenas; Goodness-of-Fit = Poder de ajustamento do modelo. Parâmetros (Cohen, 1988; Tenenhaus, Vinzi, Chatelin \& Lauro, 2005): $\mathrm{R}^{2}$ até $2 \%$ indica efeito pequeno; acima de $2 \%$ até $13 \%$ indica efeito médio; acima de $13 \%$ até $26 \%$ indica efeito grande; e GoF acima de 0,36 apresenta-se adequado. ${ }^{* *},{ }^{* *} \mathrm{e}^{*}$ indicam significância ao nível de $1 \%, 5 \%$ e $10 \%$, respectivamente. Fonte: dados da pesquisa.

Por meio da análise de caminhos realizada a partir das premissas de Baron e Kenny (1986) e instrumentalizada com auxílio do método bootstrapping, identificou-se a existência de mediação parcial dos construtos de responsabilidade ambiental na relação entre distância psicológica com intençấo de compra e lealdade do consumidor.

A responsabilidade ambiental exerce mediação parcial entre distância psicológica e intenção de compra, na medida em que o efeito direto apresenta declínio em seu coeficiente com a inclusão da mediação. Em termos percentuais, a responsabilidade ambiental medeia $87,50 \%$ dos efeitos da relaçáo analisada. Além disso, ao verificar o caminho entre a distância psicológica e a lealdade do consumidor, nota-se que a responsabilidade ambiental exerce mediação total nesta relaçáo, fato observado a partir das significâncias obtidas na análise dos coeficientes e na redução dos efeitos diretos.

Tais resultados diferem dos achados de Yu et al. (2017) na medida em que toda a cadeia de responsabilidade ambiental apresentou mediação na relação entre a distância psicológica com a intenção de compra e a lealdade do consumidor. Esses resultados podem advir das diferenças no desenho do modelo estrutural, visto que nesta investigação a ética ambiental foi considerada no mesmo nível dos padróes da autorresponsabilidade e da responsabilidade social.

A significância entre a responsabilidade ambiental e a lealdade do consumidor alinha-se com as evidências expostas por Oliver (1999), pois em seu estudo, tal relacionamento é elucidado. Adicionalmente, as constataçôes de Kautish e Sharma (2019) e Shafiei e Maleksaeidi (2020) subsidiam a importância do estudo dos aspectos comportamentais frente ao comportamento dos consumidores, em especial de jovens universitários, pois tais variáveis exercem poder preditivo em relação às suas atitudes.

Os resultados obtidos por meio da análise dos dados não permitem rejeitar a hipótese proposta nesta pesquisa, de que a relação entre distância psicológica com a intenção 
de compra e a lealdade a produtos pró-ambientais é mediada pela responsabilidade ambiental, uma vez que o objetivo da proposiçấo consiste em identificar a existência do fenômeno mediador, fato que foi confirmado por meio da análise de caminhos. Em termos de intensidade, nota-se que tal mediaçáo ocorre de forma parcial na trajetória entre responsabilidade ambiental e intençáo de compra, e total entre responsabilidade ambiental e lealdade do consumidor.

Quanto ao modelo proposto, todos os $\mathrm{R}^{2}$ dos construtos apresentaram significância ao nível de 5\%, sendo que o modelo estrutural com mediação apresentou maior poder preditivo, visto que o Goodness-of-Fit do modelo com mediaçáo foi 0,45 frente a 0,25 do modelo direto. Assim, percebe-se a relevância em abordar o efeito mediador da responsabilidade ambiental nas análises dos comportamentos dos jovens universitários do curso de Ciências Contábeis, que representam os consumidores analisados nesta pesquisa.

No que tange à distância psicológica, nota-se a partir dos resultados que o menor distanciamento do indivíduo com as mudanças climáticas fomenta a responsabilidade ambiental, sendo concordante com as discussóes de Spence et al. (2012). A aproximação junto aos respondentes com intuito de retrair o distanciamento psicológico frente às mudanças climáticas torna-se oportuna a partir da promoção da responsabilidade ambiental, visto que os resultados indicam que esta variável é capaz de mediar totalmente a relação entre distância psicológica e lealdade do consumidor.

A partir dos resultados expostos e dos elementos inerentes à teoria do nível de interpretaçáo, pode-se fomentar a responsabilidade ambiental nos estudantes do curso de Ciências Contábeis por meio de práticas e açóes de conscientização ambiental voltadas à exposição dos impactos das modificaçóes climáticas e ambientais. Acredita-se que campanhas educativas, atividades interativas e projetos de extensão que explorem as consequências dos padróes de consumo sobre as alteraçóes ambientais podem colaborar com a reduçáo do distanciamento psicológico existente.

\section{CONCLUSÃO}

Este estudo teve como objetivo verificar a relação entre distância psicológica com a intenção de compra e a lealdade a produtos pró-ambientais mediada pela responsabilidade ambiental. Para tanto, a coleta de dados foi instrumentalizada por meio de uma survey realizada junto a acadêmicos do bacharelado em Ciências Contábeis de uma universidade pública do sul do Brasil. $\mathrm{Na}$ análise dos dados, utilizou-se da técnica de modelagem de equaçóes estruturais, do método bootstrapping e das premissas de Baron e Kenny (1986) na verificação da hipótese proposta.
A identificação do efeito mediador significante da responsabilidade ambiental possibilitou que a hipótese da pesquisa náo fosse rejeitada, pois em termos de intensidade foi identificado que a responsabilidade ambiental medeia parcialmente a relaçáo entre distância psicológica e intenção de compra e totalmente a relação com a lealdade do consumidor. Os resultados ainda indicam que o modelo mediador apresenta maior poder preditivo e é mais adequado para análise do comportamento de consumo dos acadêmicos do curso de Ciências Contábeis. Tais achados induzem implicaçóes teóricas e práticas acerca da temática, que são discutidas a seguir.

\section{Implicações teóricas}

Este estudo estende o corpo de literatura teóricoempírico existente ao apontar que a compreensão da responsabilidade ambiental é um elemento-chave na identificação da intenção de compra e da lealdade a produtos pró-ambientais. De modo adicional, é reforçada a necessidade de observar variáveis que expandam as discussóes sobre preditores comportamentais, além de características observáveis, como gênero e idade, comumente abordadas na literatura. Os elementos da teoria do nível de interpretação mostraram-se adequados e pertinentes à análise do comportamento dos jovens universitários consumidores pertencentes ao curso de Ciências Contábeis, visto que a distância psicológica pode afetar a intenção de compra e lealdade destes consumidores.

A responsabilidade ambiental, com destaque para a ética ambiental, apresenta-se como preditora do comportamento dos jovens universitários que compóem a amostra da pesquisa. A ética tem sido apontada como um elemento importante e que gera preocupaçóes em relação à formação do profissional contábil. Ao verificar o relacionamento deste construto com a intenção de compra e a lealdade a produtos pró-ambientais, é reforçada a necessidade de abordar a ética em suas diferentes dimensóes com o objetivo de detectar padróes comportamentais e relacioná-los com medidas corretivas de comportamento futuro.

Em relação aos consumidores em geral, a teoria do nível de interpretação traz elementos relevantes que podem ser ampliados para esse público amplo a fim de fomentar a discussáo do comportamento de consumo, pois ao ilustrar que acontecimentos percebidos próximos aos jovens universitários tendem a receber maior atenção e importância nos julgamentos e atitudes pessoais, são abertas oportunidades de pesquisas e açóes práticas em diversos âmbitos do escopo comportamental. Por exemplo, campanhas publicitárias podem pautar as vantagens do consumo consciente a partir de efeitos sobre o meio ambiente de curto prazo a fim de promover o engajamento do indivíduo. 


\section{Implicações práticas}

Os resultados encontrados indicam que a distância psicológica pode fomentar comportamentos conscientes nos respondentes, sendo oportuno o investimento em campanhas publicitárias, açôes educativas e atividades que diminuam a noção de distanciamento dos impactos ambientais. Os elementos teóricos indicam que o fator financeiro e a qualidade percebida são levados em consideração no processo de aquisição de produtos pró-ambientais; assim, políticas de consumo e inclusão social podem ser desenvolvidas para incentivar indiretamente a compra e o uso de produtos pró-ambientais. Destaca-se também a necessidade de enfatizar o papel dos produtos pró-ambientais em ajudar a sustentabilidade ambiental e a autorresponsabilidade com o meio ambiente; portanto, as comunicaçôes publicitárias direcionados aos universitários da área contábil devem focar nos efeitos sociais do consumo de tais produtos no curto prazo, e não estritamente no aspecto financeiro.

Em relaçấo aos acadêmicos de Ciências Contábeis é oportuno incluir discussóes acerca da responsabilidade ambiental, a partir de conteúdos voltados ao consumo consciente e à sustentabilidade ambiental. Disciplinas como Contabilidade Ambiental podem abranger em seus tópicos elementos que tratam de valores sociais e éticos mostrando a importância da responsabilidade ambiental em termos sociais, expandindo os debates em sala de aula para além dos aspectos financeiros que permeiam a criação de valor econômico para a organização. Acredita-se que tais debates possam auxiliar na

\section{REFERÊNCIAS}

Afonso, M. H. F., Bornia, A. C., Echegaray, F., \& de Andrade, D. F. (2016). Comportamento de consumo sustentável: Mensuração com o uso da teoria da resposta ao item. Revista Eletrônica de Gestão Organizacional, 14, 16-29. http://dx.doi.org/10.21714/1679-18272016v14Esp.p16-29

Ariztía, T., Kleine, D., Brightwell, M. das G. S. L., Agloni, N., Afonso, R., \& Bartholo, R. (2014). Ethical consumption in Brazil and Chile: Institutional contexts and development trajectories. Journal of Cleaner Production, 63, 84-92. https://doi.org/10.1016/j.jclepro.2013.04.040

Baron, R. M., \& Kenny, D. A. (1986). The moderator-mediator variable distinction in social psychological research: Conceptual, strategic, and statistical considerations. Journal of personality and social psychology, 51(6), 1173-1182. http://doi.org/10.1037//0022-3514.51.6.1173

Brügger, A., Morton, T. A., \& Dessai, S. (2016). "Proximising” climate change reconsidered: A construal level theory perspective. Journal of Environmental Psychology, 46, 125142. http://doi.org/10.1016/j.jenvp.2016.04.004 formação de profissionais contábeis preocupados e alinhados com questôes ambientais.

\section{Limitações e pesquisas futuras}

Oportunizam-se novas investigaçóes a respeito da temática, abordando os construtos de distância psicológica e responsabilidade ambiental de modo simultâneo e em conjunto ao comportamento dos consumidores. Pesquisas podem adotar técnicas de coleta e análise de dados qualitativas para identificar a percepçáo dos respondentes acerca da temática em profundidade. De modo adicional, a responsabilidade ambiental pode ser testada em investigaçóes futuras como moderadora da relaçáo entre distância psicológica e comportamento dos consumidores. Abranger a amostra para outras áreas do conhecimento e para consumidores com diferentes perfis apresenta-se também como uma oportunidade de pesquisa.

As limitações da pesquisa advêm da escolha não probabilística da amostra. Os respondentes são jovens consumidores com acesso a informaçóes sobre a temática ambiental, podendo não representar a realidade brasileira, e o recorte temporal crossection limita o poder inferencial dos resultados. Por fim, considera-se que esta investigaçáo atingiu o objetivo proposto e expôs introspecçóes para investigaçôes futuras na referida área de pesquisa.

\section{AGRADECIMENTOS}

Os autores agradecem ao pesquisador Iago França Lopes (UFPR) pela revisão prévia deste artigo.
Chen, Y. S. (2011). Green organizational identity: sources and consequence. Management Decision, 49(3), 384-404. http://doi.org/10.1108/00251741111120761

Cohen, J. (1988). Statistical Power Analysis for the behavioral sciences (2nd ed). New York: Psychology Press.

Eckhardt, G. M., Belk, R., \& Devinney, T. M. (2010). Why don't consumers consume ethically?. Journal of Consumer Behaviour, 9(6), 426-436. https://doi.org/10.1002/b.332

Fakhrudin, I. A., Karyanto, P., \& Ramli, M. (2018). Behavioral intention and its relationship with gender: a study of green school students in Surakarta, Indonesia. Journal of Physics: Conference Series, 1022(1), 012043. http://doi.org/10.1088/1742-6596/1022/1/012043

Ferraz, S. B., Romero, C. A. B., Rebouças, S. M. D. P., \& Costa, J. S. (2016). Produtos verdes: Um estudo sobre atitude, intenção e comportamento de compra de universitários brasileiros. Revista de Administração da UFSM, 9(4), 605623. http://doi.org/10.5902/1983465912400 
Gordon-Wilson, S., \& Modi, P. (2015). Personality and older consumers' green behaviour in the UK. Futures, 71, 1-10. https://doi.org/10.1016/j.futures.2015.05.002

Gilead, M., Liberman, N., \& Maril, A. (2014). From mind to matter: Neural correlates of abstract and concrete mindsets. Social Cognitive and Affective Neuroscience, 9(5), 638-645. http://doi.org/10.1093/scan/nst031

Global Industry Analysts. (2013). Green marketing: A global strategic business report. Retrieved from: http://www. asiagreenbuildings.com/3553/green-marketing-a-globalstrategic-business-report/

Groening, C., Sarkis, J., \& Zhu, Q. (2018). Green marketing consumer-level theory review: A compendium of applied theories and further research directions. Journal of Cleaner Production, 172, 1848-1866. http://doi.org/10.1016/j.jclepro.2017.12.002.

Hair, J. F., Jr., Hult, G. T. M., Ringle, C. M., \& Sarstedt, M. (2014). A primer on partial least squares structural equation modeling (PLS-SEM). Thousand Oaks: SAGE.

Hair, J. F., Sarstedt, M., Ringle, C. M., \& Mena, J. A. (2012). An assessment of the use of partial least squares structural equation modeling in marketing research. Journal of the Academy of Marketing Science, 40(3), 414-433. https://doi.org/10.1007/s11747-011-0261-6

Henseler, J., Ringle, C.M., \&Sinkovics, R. R. (2009). The useof partial least squares path modeling in international marketing. Advances in International Marketing, 20, 277-319. https://doi.org/10.1108/S1474-7979(2009)0000020014

Institute of Medicine (US), Roundtable on Environmental Health Sciences, Research, and Medicine. (2007). Global environmental health in the 21st Century: From Governmental Regulation to Corporate Social Responsibility: Workshop Summary. Washington, DC: National Academies Press, 5, Corporate Social Responsibility. Retrieved from: https://www.ncbi.nlm.nih.gov/books/NBK53982/

Instituto Brasileiro de Geografia e Estatística. (2020). Pirâmide Etária. Retrieved from: https://educa.ibge.gov.br/jovens/ conheca-o-brasil/populacao/18318-piramide-etaria.html

Joshia, Y., \& Rahman, Z. (2015). Factors affecting green purchase behaviour and future research directions. International Strategic Management Review, 3(1-2), 128-143. https://doi.org/10.1016/j.ism.2015.04.001

Khan, H. Z., Fatima, J. K., \& Bose, S. (2019). Understanding pro-environmental behaviour of accounting and business students: Development of a conceptual framework. Ethics and Sustainability in Accounting and Finance, 1, 69-82. http://doi.org/10.1007/978-981-13-3203-6 5

Kautish, P., \& Sharma, R. (2019). Study on relationships among terminal and instrumental values, environmental consciousness and behavioral intentions for green products. Journal of Indian Business Research. https://doi.org/10.1108/JIBR-01-2018-0013.

Kelly, M., \& Alam, M. (2009). Educating accounting students in the age of sustainability. Australasian Accounting, Business and Finance Journal, 3(4), 3. Retrieved from: https://ro.uow.edu.au/aabf//vol3/iss4/3/
Lecours, V., Devillers, R., Schneider, D. C., Lucieer, V. L., Brown, C. U. J., Edinger, E. J. (2015). Spatial scale and geographic context in benthic habitat mapping: review and future directions. Marine Ecology Progress Series, 535, 259-284. http://doi.org/10.3354/meps11378

Lee, Y.K. (2017). A comparative study of green purchase intention between Korean and Chinese consumers: The moderating role of collectivism. Sustainability, 9(10), 1930. https://doi.org/10.3390/su9101930

McCabe, D. L., Butterfield, K. D., \& Treviño, L. K. (2006). Academic dishonesty in graduate business programs: Prevalence, causes, and proposed action. Academy of Management Learning and Education, 5(3), 294-305. https://doi.org/10.5465/amle.2006.22697018

McDonald, R. I., Chai, H. Y., \& Newell, B. R. (2015). Personal experience and the 'psychological distance' of climate change: An integrative review. Journal of Environmental Psychology, 44, 109-118. https://doi.org/10.1016/j.jenvp.2015.10.003

Meriac, J. P. (2012). Work ethic and academic performance: Predicting citizenship and counterproductive behavior. Learning and Individual Differences, 22(4), 549-553. https://doi.org/10.1016/j.lindif.2012.03.015

Mohiuddin, M., Al Mamun, A., Syed, F. A., Masud, MM., \& Su, Z. (2018). Environmental knowledge, awareness, and business school students' intentions to purchase green vehicles in emerging countries. Sustainability, 10(5), 1534. https://doi.org/10.3390/su10051534

Oliver, R. L. (1999). Whence consumer loyalty? The Journal of Marketing, 63, 33-44. https://doi.org/10.2307/1252099

Sacchi, S., Riva, P., \& Aceto, A. (2016). Myopic about climate change: Cognitive style, psychological distance, and environmentalism. Journal of Experimental Social Psychology, 65, 68-73. https://doi.org/10.1016/j.jesp.2016.03.006

Sanchez, G. (2013). PLS path modeling with R. Berkeley: Trowchez Editions.

Serviço de Proteção ao Crédito. (2019). Consumo Consciente 2019. Retrieved from: https://www.spcbrasil.org.br/ wpimprensa/wp-content/uploads/2019/06/analise compras online junho 2019.pdf

Shafiei, A., \& Maleksaeidi, H. (2020). Pro-environmental behavior of university students: Application of protection motivation theory. Global Ecology and Conservation, 22, e00908. https://doi.org/10.1016/j.gecco.2020.e00908

Singh, A. S., Zwickle, A., Bruskotter, J. T., \& Wilson, R. (2017). The perceived psychological distance of climate change impacts and its influence on support for adaptation policy. Environmental Science of Policy, 73, 93-99. https://doi.org/10.1016/j.envsci.2017.04.011

Spence, A., Poortinga, W., \& Pidgeon, N. (2012). The psychological distance of climate change. Risk Analysis, 32(6), 957-972. http://doi.org/10.1111/j.1539-6924.2011.01695.x

Tenenhaus, M., Vinzi, V.E., Chatelin, Y \& Lauro, C. (2005). PLS path modeling. Computational Statistics \& Data Analysis. 48(1), 159-205. https://doi.org/10.1016/j.csda.2004.03.005 
Trenberth, K. E. (2012). Framing the way to relate climate extremes to climate change. Climatic change, 115, 283-290. https://doi.org/10.1007/s10584-012-0441-5

Trivedi, R. H., Patel, J. D., \& Acharya, N. (2018). Causality analysis of media influence on environmental attitude, intention and behaviors leading to green purchasing. Journal of cleaner production, 196, 11-22. https://doi.org/10.1016/j.jclepro.2018.06.024

Trope, Y., \& Liberman, N. (2010). Construal-level theory of psychological distance. Psychological review, 117(2), 440-463. http://doi.org/10.1037/a0018963

United States of America. Environmental Protection Agency. (2015). Laws \& Regulations. Retrieved from: http://www2.epa.gov/laws-regulations

\section{Autoria}

\section{Alison Martins Meurer*}

Universidade Federal do Paraná, Programa de Pós-Graduação em Contabilidade

Av. Prefeito Lothário Meissner, no 632, Jardim Botânico, 80210-170, Curitiba, PR, Brasil.

E-mail: alisonmmeurer@gmail.com

(D) https://orcid.org/0000-0002-3704-933X

\section{Cristina Viana de Jesus}

Universidade Federal do Paraná, Programa de Pós-Graduação em Contabilidade

Av. Prefeito Lothário Meissner, no 632, Jardim Botânico, 80210-170, Curitiba, PR, Brasil.

E-mail: cryssviana1@gmail.com

(D) https://orcid.org/0000-0003-0375-4310

\section{Luiz Panhoca}

Universidade Federal do Paraná, Programa de Pós-Graduação em Contabilidade

Av. Prefeito Lothário Meissner, no 632, Jardim Botânico, 80210-170, Curitiba, PR, Brasil.

E-mail: panhoca.luiz@gmail.com

(D) https://orcid.org/0000-0002-0839-1611

* Autor Correspondente

\section{Financiamento}

Os autores agradecem à Coordenação de Aperfeiçoamento de Pessoal de Nível Superior (CAPES) pelo apoio financeiro concedido.

\section{Verificação de Plágio}

A RAC mantém a prática de submeter todos os documentos aprovados para publicação à verificação de plágio, mediante o emprego de ferramentas específicas, e.g.: iThenticate.

\section{Direitos Autorais}

A RAC detém os direitos autorais deste conteúdo.
Vitell, S. J. (2015). A case for consumer social responsibility (CnSR): Including a selected review of consumer ethics/social responsibility research. Journal of Business Ethics, 130(4), 767774. http://doi.org/10.1007/s10551-014-2110-2

Yu, T. Y., Yu, T. K., \& Chao, C. M. (2017). Understanding Taiwanese undergraduate students' pro-environmental behavioral intention towards green products in the fight against climate change. Journal of Cleaner Production, 161(10), 390-402. https://doi.org/10.1016/j.jclepro.2017.05.115

White, K., MacDonnell, R., \& Ellard, J. H. (2012). Belief in a just world: Consumer intentions and behaviors toward ethical products. Journal of Marketing, 76(1), 103-118. https://doi.org/10.2307/41406841

\section{Contribuições dos Autores}

$1^{\circ}$ autor: conceitualização (igual); análise formal (igual); investigação (igual); metodologia (igual); validação (igual); visualização (igual); redação - rascunho original (igual); redação-revisão e edição (igual).

$2^{\mathrm{a}}$ autora: metodologia (apoio); recursos (apoio); curadoria de dados (apoio); aquisição de financiamento (apoio).

$3^{\circ}$ autor: análise formal (igual); investigação (igual); metodologia (igual); supervisão (igual); validação (igual); redação - rascunho original (igual); redação - revisão e ediçẫo (líder).

\section{Conflito de Interesses}

Os autores informaram que não há conflito de interesses.

\section{Método de Revisão por Pares}

Este conteúdo foi avaliado utilizando o processo de revisão por pares duplo-cego (double-blind peer-review). A divulgação das informaçôes dos pareceristas constantes na primeira página é feita somente após a conclusão do processo avaliativo, e com o consentimento voluntário dos respectivos pareceristas.

\section{Disponibilidade dos Dados}

Todos os dados e materiais foram disponibilizados publicamente por meio da plataforma Harvard Dataverse e podem ser acessados em:

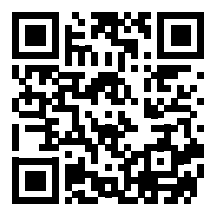

Alison Martins Meurer; Cristina Viana de Jesus; Luiz Panhoca, 2020, "Replication Data for: Environmental Responsibility, Psychological Distance, and Environmental Consumption: Mediation in Accounting Students", Harvard Dataverse, V1. https://doi.org/10.7910/DVN/GWCMHF

A RAC incentiva o compartilhamento de dados mas, por observância a ditames éticos, não demanda a divulgação de qualquer meio de identificação de sujeitos de pesquisa, preservando a privacidade dos sujeitos de pesquisa. A prática de open data é viabilizar a reproducibilidade de resultados, e assegurar a irrestrita transparência dos resultados da pesquisa publicada, sem que seja demandada a identidade de sujeitos de pesquisa. 


\section{ANEXO I}

Tabela 1A. Bloco 1 - Comportamento dos consumidores em relação a produtos pró-ambientais.

\begin{tabular}{|c|c|}
\hline \multirow{4}{*}{$\begin{array}{l}\text { Distância } \\
\text { psicológica }\end{array}$} & 1 - Mudanças climáticas provavelmente terão um grande impacto sobre as pessoas. \\
\hline & 2 - Estou certo que as mudanças climáticas realmente estáo acontecendo. \\
\hline & 3 - Se houver, o Brasil sentirá os efeitos das mudanças climáticas. \\
\hline & 4 - Mudanças climáticas afetarão áreas que estão próximas ao Brasil. \\
\hline \multirow{5}{*}{$\begin{array}{l}\text { Responsabilidade } \\
\text { social }\end{array}$} & 5 - Eu recomendo produtos verdes e/ou orgânicos para meus amigos e familiares. \\
\hline & 6 - Sinto-me moralmente obrigado a comprar produtos verdes e/ou orgânicos. \\
\hline & 7 - Participo de atividades que visam a proteger e melhorar a qualidade do meio ambiente. \\
\hline & $\begin{array}{l}8 \text { - Eu apoio organizaçóes não governamentais que trabalham para minimizar os impactos negativos causados por outras } \\
\text { organizaçôes ao meio ambiente. }\end{array}$ \\
\hline & 9 - Devemos assumir a responsabilidade por questóes ambientais. \\
\hline \multirow{5}{*}{$\begin{array}{l}\text { Comportamento } \\
\text { ético }\end{array}$} & 10 - Evito comprar produtos potencialmente prejudiciais ao meio ambiente. \\
\hline & 11 - Quando uso produtos ecológicos e/ou orgânicos, sinto que posso ajudar o meio ambiente. \\
\hline & 12 - Sinto-me mais confortável quando uso produtos ecológicos ao invés de produtos não ecológicos. \\
\hline & 13 - Procuro comprar produtos feitos com materiais reciclados. \\
\hline & 14 - Para manter uma economia saudável, todos os seres vivos têm o direito moral de existir. \\
\hline \multirow{4}{*}{$\begin{array}{l}\text { Autorresponsabilidade } \\
\text { ambiental }\end{array}$} & 15 - Considero questôes ambientais ao realizar uma compra. \\
\hline & 16 - Já alterei a opção de compra de algum produto importante por razōes ecológicas. \\
\hline & 17 - Eu acho que os indivíduos têm a responsabilidade de proteger o meio ambiente. \\
\hline & 18 - Quando uso produtos ecológicos, sinto que apoio a preservação ambiental. \\
\hline \multirow{5}{*}{ Intenção de compra } & 19 - Em um futuro próximo, estou disposto a comprar produtos ecológicos. \\
\hline & 20 - Em um futuro próximo, estou disposto a comprar produtos com uma marca ecológica. \\
\hline & 21 - Em um futuro próximo, planejo comprar somente produtos com uma marca ecológica. \\
\hline & 22 - Em um futuro próximo, vou comprar somente produtos que evitam o uso de materiais químicos corrosivos. \\
\hline & 23 - Em um futuro próximo, comprarei produtos feitos de materiais recicláveis. \\
\hline \multirow{5}{*}{ Lealdade do consumidor } & 24 - Definitivamente vou continuar consumindo produtos ecológicos e recicláveis. \\
\hline & 25 - Estou disposto a pagar mais dinheiro por produtos ecológicos. \\
\hline & 26 - Os produtos ecológicos são sempre a minha primeira escolha. \\
\hline & 27 - Eu me considero leal aos produtos ecológicos. \\
\hline & 28 - Se os produtos ecológicos não estiverem disponíveis na loja, eu não compro outros produtos. \\
\hline
\end{tabular}

Nota. Fonte: Adaptado de Yu et al. (2017). 